\title{
FACT-TRaCKING BELIEF AND THE BACKWARD Clock: A REPLY TO ADAMS, BARKER AND CLARKE
}

\author{
JOHN N. WILLIAMS \\ Department of History, Philosophy and Religious Studies \\ School of Humanities and Social Sciences \\ Nazarbayev University \\ 53 Kabanbay Batyr Avenue \\ Astana, 01000 \\ Kazakistan \\ williamsjohn276@gmail.com
}

\begin{abstract}
Article info
CDD: 121

\section{Keywords:}

Backward Clock

Adams, Barker and Clarke

Fact-tracking belief

Sensitivity
\end{abstract}

Received: 17.07.2018; Revised: 30.08.2018; Accepted: 03.09.2018

DOI: http://dx.doi.org/10.1590/0100-6045.2018.V41N3.JW

Abstract: In "The Backward Clock, Truth-Tracking, and Safety" (2015), Neil Sinhababu and I gave Backward Clock, a counterexample to Robert Nozick's (1981) truth-tracking analysis of knowledge. In "Knowledge as Fact-Tracking True Belief" (2017), Fred Adams, John Barker and Murray Clarke propose that a true belief constitutes knowledge if and only if it is based on reasons that are sensitive to the fact that makes it true, that is, reasons that wouldn't obtain if the belief weren't true. They argue that their analysis evades Backward Clock. Here I show that it doesn't. Backward Clock likewise shows their analysis to be too weak. The broader lesson seems to be that Backward Clock tells us the time is up for purely modal analyses of knowledge. 
In "The Backward Clock, Truth-Tracking, and Safety" (2015), Neil Sinhababu and I gave Backward Clock, a counterexample to Robert Nozick's (1981) truth-tracking analysis of knowledge. In "Knowledge as Fact-Tracking True Belief" (2017), Fred Adams, John Barker and Murray Clarke propose that a true belief constitutes knowledge if and only if it is based on reasons that are sensitive to the fact that makes it true, that is, reasons that wouldn't obtain if the belief weren't true. They argue that their analysis evades Backward Clock. Here I show that it doesn't. Backward Clock likewise shows their analysis to be too weak.

\section{THE Backward Clock and the Truth- TRACKING ANALYSIS OF KNOWLEDGE}

Nozick's analysis is that

$S$ knows that $p$, using method $M$ of arriving at a belief whether $p$, if and only if

(1) $p$

(2) $S$ believes, using $M$, that $p$

(3) In the closest (that is, most similar) worlds to the actual world in which not- $p$ (and in which $S$ uses $M), S$ does not believe that $p$

(4) In the closest (that is, most similar) worlds to the actual world in which $p$ (and in which $S$ uses $M$ ), S believes that $p(1981,179)$.

(3) is commonly known as the "sensitivity condition," meaning that $S$ 's belief that $p$ is sensitive to falsehood; roughly, she would not have that belief if it were false. (4) is commonly known as the "adherence condition," meaning that $S$ 's belief that $p$ adheres to the truth; roughly, were she to have that belief in slightly changed circumstances, then it 
would still be true. A belief that is both sensitive to falsehood and adherent to truth is said to be "truth-tracking." This analysis seems to explain why you may acquire knowledge in Normal Clock, as follows.

You habitually nap between $4 \mathrm{pm}$ and $5 \mathrm{pm}$. Your method of ascertaining the time you wake is to look at your clock, one you know has always worked perfectly reliably. This clock is analogue so its hands sweep its face continuously. However, it has no second hand. ${ }^{1}$ Awaking at 4:30 pm, you see that its hands point to $4: 30 \mathrm{pm}$. Accordingly, you form the belief that it is $4: 30 \mathrm{pm}$. And it is indeed 4:30 pm because the clock has continued to work perfectly reliably.

Your true belief that it is $4: 30 \mathrm{pm}$ is sensitive to falsehood. Had it been any time other than 4:30 pm when you observe the position of the hands of your clock, then you would not believe that it is $4: 30 \mathrm{pm}$. In other words, in the closest worlds to the actual world in which it is not $4: 30 \mathrm{pm}$ (and in which you observe the position of the hands of your clock to tell the time), you do not form the false belief that it is 4:30 pm. Instead you form some other true belief about what time it is. For example, had it been 4:31 pm when you observe the position of the hands of your clock, then you would not form the false belief that it is $4: 30 \mathrm{pm}$. Instead you would form the true belief that it is $4: 31 \mathrm{pm}$.

Your true belief also satisfies Nozick's truth-adherence condition (4). If you had observed the position of the hands

1 We stipulated this to ensure parity with two other examples, Stopped Clock and Backward Clock. 
of your clock while being slightly closer to it, then you would still believe that it is $4: 30 \mathrm{pm}$. In other words, in worlds close to the actual world in which it is 4:30 pm (and in which you observe the position of the hands of your clock in order to ascertain the time), you believe that it is $4: 30 \mathrm{pm}$.

Nozick's sensitivity condition deals nicely with Gettier cases of justified true belief that fail to count as knowledge such as Stopped Clock, as follows.

You habitually nap between $4 \mathrm{pm}$ and $5 \mathrm{pm}$. Your method of ascertaining the time you wake is to look at your clock, one you know has always worked perfectly reliably. Like Normal Clock, it has an analogue design so its hands are supposed to sweep its face continuously. However, it has no second hand. Awaking at 4:30 pm, you see that its hands point to $4: 30$ $\mathrm{pm}$. Accordingly, you form the belief that it is 4:30 pm. And it is indeed 4:30 pm because exactly twenty-four hours ago a stray fleck of dust chanced to enter the clock's mechanism, stopping it.

You do not know that it is 4:30 pm. You were lucky to look at the clock exactly twenty-four hours after it stopped working, at the only instant during the hour when you nap at which its hands could have pointed to the correct time. Nozick's analysis accommodates your ignorance, because your belief that it is $4: 30 \mathrm{pm}$ is insensitive to falsehood. If it were not 4:30 pm but some other time, then by observing the position of the hands of your clock, you would still believe that it is 4:30 pm. In other words, in possible worlds close to the actual world in which it is not 4:30 pm but, say, $4: 31 \mathrm{pm}$ (and in which you observe the position of the hands of your clock to tell the time), you form the false belief that it is $4: 30 \mathrm{pm}$. 
But now consider Backward Clock, originally presented as follows.

You habitually nap between $4 \mathrm{pm}$ and $5 \mathrm{pm}$. Your method of ascertaining the time you wake is to look at your clock, one you know has always worked perfectly reliably. Unbeknownst to you, your clock is a special model designed by a cult that regards the hour starting from 4 pm today as cursed, and wants clocks not to run forwards during that hour. So your clock is designed to run perfectly reliably backwards during that hour. At $4 \mathrm{pm}$ the hands of the clock jumped to $5 \mathrm{pm}$, and it has been running reliably backwards since then. This clock is analogue so its hands sweep its face continuously, but it has no second hand so you cannot tell that it is running backwards from a quick glance. Awaking, you look at the clock at exactly 4:30 pm and observe that its hands point to $4: 30 \mathrm{pm}$. Accordingly, you form the belief that it is 4:30 pm (Williams and Sinhababu 2017, 48).

You do not know that it is $4: 30$ pm any more than you do in Stopped Clock. For again you are lucky to look at it at exactly 4:30 pm, at the only instant during the hour when you nap at which its hands could point to the correct time.

Your true belief that it is $4: 30 \mathrm{pm}$ is truth-adherent. Had you looked at the clock at 4:30 pm while being slightly closer to it, then you would still believe that it is $4: 30 \mathrm{pm}$. In other words, in worlds close to the actual world in which it is $4: 30$ $\mathrm{pm}$ (and in which you observe the position of the hands of your clock to tell the time), you believe that it is $4: 30 \mathrm{pm}$.

Surprisingly perhaps, your true belief is also sensitive to falsehood. If it were not 4:30 pm but some other time, then by observing the position of the hands of your clock, you 
would not believe that it is $4: 30 \mathrm{pm}$. Instead you would form some other false belief about what time it is. For example, if you had looked at your clock at 4:31 pm, then you would not form the false belief that it is $4: 30 \mathrm{pm}$. Instead you would form the false belief that it is $4: 29 \mathrm{pm}$. Thus the truthtracking analysis is too weak, predicting knowledge where there is ignorance.

\section{THE BACKWARD CLOCK AND KNOWLEDGE AS FACT- TRACKING BELIEF}

Adams et al propose the following analysis of knowledge.

$S$ knows that $p$ if and only if

(1) It is the case that $p$

(2) $S$ believes that $p$ on the basis of reasons, $R$

(3) R's being the case is sensitive to $p$ 's being the case, i.e., if $p$ weren't the case, then $R$ wouldn't be the case $(2017,5)$.

They elucidate condition (2) as follows.

$S$ believes that $p$ on the basis of a reason, $R$, iff: either (i) $R$ is among $S$ 's reasons for believing that $p$, and $R$ consists of one or more experiential states of $S$; or (ii) $S$ 's believing $R$ to be the case is among $S$ 's reasons for believing that $p$, and $S$ knows that $R$ is the case (Adams et al 2017, 5)

They add that the conditional in condition (3) is to be taken as a "relevant" conditional such that these "are true only if the antecedent, together with existing conditions and laws of logic, laws of nature, etc., implies the consequent" (Adams et al 2017, 24). 
Adams et als analysis - henceforth the "ABC analysis"is strongly reminiscent of Dretske's early (1971) "conclusive reasons" analysis of knowledge. ${ }^{2}$ Like Nozick's, it contains a sensitivity to falsehood condition, although it drops his appeal to methods, instead making reasons, rather than beliefs, sensitive to falsehood. Unlike Nozick's, the ABC analysis has no adherence to truth condition.

Backward Clock shows the $\mathrm{ABC}$ analysis to be too weak. It is indeed 4:30 pm, so condition (1) is satisfied. You believe that it is $4: 30 \mathrm{pm}$ on the basis of the conjunctive reason that the hands of your clock point to 4:30 pm and that your clock has always worked perfectly reliably as an indicator of the time. We may stipulate that you know that the hands of your clock point to 4:30 $\mathrm{pm}$. Since it is already part of the example that you know that your clock has always worked perfectly reliably as an indicator of the time, you know that the hands of your clock point to $4: 30 \mathrm{pm}$ and that your clock has always worked perfectly reliably as an indicator of the time. Thus as elucidated by Adams et al, condition (2) is satisfied.

This reason is sensitive to its being 4:30 pm. In other words, as Adams et al elucidate a sensitive reason, if it were not 4:30 pm, then it would not be the case both that the

2 Dretske's early (1971) analysis is as follows.

$S$ knows that $p$ in circumstances $C$ if and only if

(1) $S$ believes that $p$ (without doubt, reservation or question) on the basis of $R$.

(2) In $C, R$ would not be the case unless $p$ were the case.

(3) Either $S$ knows that $R$, or $R$ is some experiential state of $S$ (Dretske 1971, 12-13).

where $C$ is "logically and causally independent of the state of affairs expressed by $p$ " Dretske 1971, 7-8). 
hands of your clock point to 4:30 pm and your clock has always worked perfectly reliably as an indicator of the time. This is because the hands of your clock would not point to 4:30 pm, since your clock runs perfectly reliably backwards from 5:00 pm to 4:00 pm. Had it been any other time during the hour that you nap when you observe the position of the hands of your clock, you would not believe that it is 4:30 pm. Instead you would form some other false belief about what time it is. For example, if you had looked at your clock at 4:29 pm, then you would not form the false belief that it is 4:30 pm. Instead you would form the false belief that it is 4:31 pm. Finally, the conditional in condition (3) is "relevant". Its being a time other than 4:30 pm, together with actual temporal processes still in operation and the mechanism of your clock, implies that the hands of your clock do not point to $4: 30 \mathrm{pm}$. This is what makes it true that if it were not 4:30 pm, then the hands of your clock would not point to 4:30 pm. So condition (3) is satisfied. Thus the $\mathrm{ABC}$ analysis predicts that you know that it is $4: 30 \mathrm{pm}$. You don't. The analysis is too weak, predicting knowledge where there is ignorance.

\section{ADAMS ET AL'S ATTEMPT TO EVADE THE BACKWARD ClOCK}

Adams et al single out our explanation of why Backward Clock runs perfectly reliably backwards from $5 \mathrm{pm}$ to $4 \mathrm{pm}$. This was that "your clock is a special model designed by a cult that regards the hour starting from 4 pm today as cursed, and wants clocks not to run forwards during that hour." They say that "this can be interpreted in at least two ways" (Adams et al 2017, 20). On the first, the designers of your clock have the intention to deceive you about the time. On the second, the designers intend to use the clock among each other, on the common knowledge that the clock runs 
perfectly reliably backwards from 5:00 pm to 4:00 pm. These "interpretations" would be more accurately called speculations about the cult's intentions. They then argue that on either "interpretation", our example fails. Calling the victim of the clock "John", they write as follows.

On the first interpretation, which we'll call the Untrustworthy Backward-Clock case, the cult's dishonest clockmakers have designed their special clocks to deceive viewers during the cursed hour. At 4:30 pm, John looks at his clock and believes that the time is $4: 30 \mathrm{pm}$ on the basis of the clock's saying that it's $4: 30 \mathrm{pm}$ (Adams et al, 2017, 20-21, my italics).

This concedes that condition (2) is satisfied. They continue as follows.

Since the clock was designed to fool viewers during the cursed hour, the clock isn't trustworthy (Adams et al, 2017, 21).

So far so good for Adams et al. Your clock is unreliable as an indicator of the correct time. At all times other than 4:30 pm, the hands of your clock do not point to the correct time. But then they immediately add the following startling claim.

... if hadn't been the case the time was 4:30 pm, it might nonetheless have been the case that the clock said it was 4:30 pm anyway (Adams et al, 2017, 21).

This claim is false. In our description of the example, we stipulated that "your clock is designed to run perfectly reliably backwards during that hour". Given that it does 
indeed run perfectly reliably backwards from 5:00 pm to 4:00 $\mathrm{pm}$, it is reliable in the way its mechanism operates. By this I mean that were one to know (which in fact, you do not) the way its mechanism operates, then one could unfailingly predict the position of its hands on the basis of what time it actually is. ${ }^{3}$ Given this, in Backward Clock, the only time its hands can point to $4: 30 \mathrm{pm}$ is at 4:30 $\mathrm{pm}$.

Perhaps Adams et al have in mind the possibility that although your clock is designed run perfectly reliably backwards from 5:00 pm to 4:00 pm, it doesn't fulfil its purpose. This is strongly suggested by a later passage, as follows.

Perhaps John's clock was the work of a neophyte who failed to replicate the design of the cult's other clocks, which run backwards at a slow speed to display an incorrect time all during the cursed hour (Adams et al, 2017, 21).

This is a very uncharitable reading of our example. We didn't think at all about any broader intentions of designers. We meant "designed" factively; your clock is successfully designed to run perfectly reliably backwards during that hour. "Contrived" might have been a better choice of words. It doesn't matter. I am free to just stipulate that your clock runs perfectly reliably backwards from 5:00 pm to 4:00 pm.

\footnotetext{
3 Thus knowing that Stopped Clock is stopped at 4:30 pm, one may predict that whatever time it is, its hands indicate that it is $4: 30 \mathrm{pm}$. Knowing that the mechanism of Normal Clock is reliably driving its hands forwards at a certain uniform speed and that it is, for example, 4:31 pm, one may predict that its hands indicate 4:31 pm. Knowing that the mechanism of Backward Clock is reliably driving its hands backwards at a certain uniform speed from 5:00 pm and that it is, for example, 4:31 pm, one may predict that its hands indicate 4:29 pm.
} 
Adams et al end their discussion of the first "interpretation" as follows.

Nevertheless, his untrustworthy clock doesn't enable him to learn that it's 4:30. To paraphrase Dretske, you can learn what the time is from clocks, yes, but only from clocks that wouldn't say what the time is unless it were true (Adams et al, 2017, 21).

Whether or not the paraphrase is true, I agree that you couldn't learn that it is $4: 30 \mathrm{pm}$, because whatever you learn you know. You can't know that it is 4:30 pm because your belief that it is $4: 30 \mathrm{pm}$ is luckily true. That however is grist to my mill, since (1)-(3) of the $\mathrm{ABC}$ analysis remain true, at least if your clock runs perfectly reliably backwards from 5:00 $\mathrm{pm}$ to 4:00 pm, as we are free to stipulate. Thus even on the first speculation that your clock was designed by someone with intentions to deceive you about the time, Backward Clock — taken with a pinch of charity - is unscathed.

Let us now turn to Adams et als second speculation that the designers intend to use the clock among each other, on the common knowledge that the clock runs perfectly reliably backwards from 5:00 pm to 4:00 pm. They begin as follows.

On the second interpretation, which we'll call the Proprietary Backward-Clock case, the cult's clocks are meant to be viewed only by cult members, who know that the clocks run backwards during the cursed hour and can readily use them to ascertain the correct time even during these periods. The clockmakers, who don't desire to deceive anyone, teach fellow cult members how to determine what the special clocks say during the cursed hour. 
For instance, members "in the know" understand that when the hands of a special clock are in what would normally be the $4: 35$ pm position, the clock is really saying that the time is $4: 25 \mathrm{pm}$, and when the hands are in what would normally be the 4:25 pm position, the clock is really saying that the time is $4: 35$ pm (Adams et al, 2017, 21).

So far so good. They continue as follows.

Since John doesn't know what his clock is saying during the cursed hour, his true belief that the time is $4: 30 \mathrm{pm}$ fails to qualify as knowledge (Adams et al, 2017, 21).

I am unsure what to make of the premise. Are clocks the sorts of things that can "say" the time? ${ }^{4}$ Perhaps Adams et al think that to know what the clock "says" is to know how to use your observations of the positions of its hands in order to know what time it is. This means that you must know not only what positions these are but also how such positions are intended to represent the time. All that is perfectly true-but also equally true of Normal Clock, in which you do know that it is $4: 30 \mathrm{pm}$.

However as I have already said, I agree that you cannot know that it is $4: 30 \mathrm{pm}$. Your belief that it is $4: 30 \mathrm{pm}$ is luckily true. Adams et al continue as follows.

He believes that it's 4:30 pm because he believes that the clock says so, but he is in no position to tell that this is what the clock says (Adams et al, 2017, 21).

\footnotetext{
${ }^{4}$ Relatedly, John Biro $(2013,58)$ argues that a stopped clock does
} not "show" any particular time. 
I don't think that this is the right way to describe matters. You believe that it is 4:30 pm because you believe, or know, that the hands of your clock point to $4: 30 \mathrm{pm}$. That is equally true of Normal Clock. Are you in a position to "tell that this is what the clock says"? Well, in one way you are. You know what time of the day is normally designated by " 4.30 pm", just as you know this in Normal Clock and Stopped Clock. But yes, of course the cult, but not you, know how they intend positions of the hands of the clock to represent the time to each other.

Adams et al continue as follows.

Unlike cult members, he doesn't know how to "tell time" during the cursed hour by means of this clock (Adams et al, 2017, 21).

If this means that you cannot use the clock in the way the cult members do, then this is true. If it means that you cannot come to know what time it is by using your clock at any time between 4:00 pm and 5:00 pm, then again it is true. The only time at which you can acquire a true belief about the time is when it is true-but only luckily true. The same holds for Stopped Clock.

So far, in the spirit of charity, I am not at loggerheads with Adams et al. But now they immediately terminate their discussion with the following argument:

John's belief isn't based on the clock's saying that it's $4: 30 \mathrm{pm}$, and therefore isn't based on a sensitive reason (Adams et al, 2017, 21).

Again, I am unsure how we are to take the "sayings" of clocks. It doesn't really matter. What matters is that your reason for thinking that it is $4: 30 \mathrm{pm}$ is that you believe, or know, that the hands of your clock point to $4: 30 \mathrm{pm}$ 
(together with your knowledge that your clock has always worked perfectly reliably as an indicator of the time). Or we might say that your reason is your experience of the hands apparently pointing to $4: 30 \mathrm{pm}$. Either way, your reason is sensitive. If it were not $4: 30 \mathrm{pm}$, then the hands of your clock would not point to $4: 30 \mathrm{pm}$. For example, if it were $4: 15 \mathrm{pm}$ then the hands of your clock would not point to $4: 30 \mathrm{pm}$. Instead they would point to 4:45 pm. Instead of experiencing the hands apparently pointing to $4: 30 \mathrm{pm}$, you would experience them apparently pointing to $4: 45 \mathrm{pm}$.

So your true belief that it is $4: 30 \mathrm{pm}$ is based on a sensitive reason. But of course, you don't know that it is $4: 30 \mathrm{pm}$. The $\mathrm{ABC}$ analysis is too weak, even on the speculation that the designers intend to use the clock among each other, on the common knowledge that the clock runs perfectly reliably backwards from 5:00 pm to 4:00 pm.

Even if I were wrong about all this, who says that these are the only interpretations of the cult's intentions? Perhaps the cult intended to symbolise the cursed nature of the hour with a seemingly unnatural phenomenon. It doesn't matter. All the example needs is the stipulation that the clock runs perfectly reliably backwards from 5:00 pm to 4:00 pm. The intentions of designers are an inessential feature of the example. Indeed, we could dispense with the cult entirely. Instead we could stipulate that the mechanisms of both Backward Clock and Stopped Clock actually operate the way that they do, not by design but by luck. This is exemplified by Bugged Backward Clock, as follows.

You habitually nap between 4:00 pm and 5:00 $\mathrm{pm}$. Your method of ascertaining the time you wake is to observe, between 4:00 pm and 5:00 $\mathrm{pm}$, the position of the hands of your clock, one you know has always worked perfectly reliably as an indicator of the correct time. This clock is analogue so its hands sweep its face 
continuously. However, it has no second-hand. Awaking at 4:30 pm, you observe, and come to know, that its hands point to $4: 30 \mathrm{pm}$. On the basis of this reason you form the belief that it is $4: 30 \mathrm{pm}$. And it is indeed 4:30 pm because unbeknownst to you, the clock has continued to work perfectly reliably until $4.00 \mathrm{pm}$, when a bug in the programming of its microchip circuit caused its hands to jump to 5:00 pm and then run perfectly reliably backwards from 5:00 pm to 4:00 pm.

Your true belief that it is $4: 30 \mathrm{pm}$ is based upon your reason that the hands of your clock point to $4: 30 \mathrm{pm}$, together with your knowledge that your clock has always worked perfectly reliably as an indicator of the correct time. You also have background knowledge of how positions of the hands of your clock are supposed to normally represent time. So conditions (1) and (2) of the ABC analysis are satisfied.

Your reason's being true is sensitive to it being 4:30 pm, i.e. if it were not 4:30 pm, then your reason would not be true. If it were not 4:30 pm but some other time during the hour that you nap, then the hands of your clock would not point to 4:30 pm, but to some other time. For example, if it were $4: 45 \mathrm{pm}$, then the hands would point to $4: 15 \mathrm{pm}$. This is because your clock runs perfectly reliably backwards from 5:00 pm to 4:00 pm. The conditional involved is unparadoxically true. It being, say, 4:45 pm, together with actual temporal processes still in operation and the mechanism of your clock, causes its hands to point to 4:15 $\mathrm{pm}$. But you do not know that it is 4:30 pm.

Adams et al wind up their defence with their Bolivian Backward Clock, as follows. 
While vacationing in Bolivia, Gertrude suffers a stroke, loses consciousness, and is taken to a hospital in La Paz. At 11:55 am, she briefly regains consciousness and, upon looking out the window, sees the Bolivian Congress Building, which features a clock that (unbeknownst to her) runs backwards. Although she cannot read the numerals on the clock's face, at 11:55 am the clock's hands appear to her to be in the 12:05 pm position, and she believes that the time is 12:05 pm. At 12:05 pm the next day, she briefly regains consciousness, sees the clock's hands in what appears to her to be the 11:55 am position, and believes that the time is 11:55 am. At noon the next day, she briefly regains consciousness, sees the clock's hands in what appears to her to be the 12:00 pm position, and believes that the time is 12:00 pm (Adams et al, 2017, 21-22).

Adams et al do not tell us anything about the reliability with which the hands of the clock move backwards. Let us assume they move perfectly reliably backwards; at noon they point to the position for 12 and then move continuously backward at a certain uniform speed so that at $6 \mathrm{pm}$ they point to the position for 6 and so on. Since Gertrude is confined to a hospital, it also seems harmless to assume that the occasions on which she may see the clock are confined to daylight hours, thus avoiding the complication that the hands may indicate to her the correct time at 12 midnight as well as 12 noon. ${ }^{5}$ Adams et al continue as follows.

\footnotetext{
${ }^{5}$ In fact, the actual clock on the Bolivian Congress Building has its numerals arranged counter-clockwise to match the counterclockwise movement of its hands, so that while the positions for 12 and 6 remain the same, the positions for 3 and 9 are reversed.
} 
Unlike the residents of $\mathrm{La} \mathrm{Paz}$, she doesn't know how to "tell time" by means of the Bolivian Congress Building's clock (Adams et al, 2017, 22).

This is true in the sense that she cannot use the clock the way the residents do. It is also true in the sense that she cannot gain knowledge of what time it is by means of the clock. Given that she mistakes the clock for a normal clock, the only time at which she can acquire a true belief about the time is when it is true-but only luckily true. That is when she happens to observe it at noon. Now Adams et al conclude as follows.

Consequently, even though her belief that the time is $12: 00 \mathrm{pm}$ is true, it fails to qualify as knowledge because she doesn't understand what the clock says about the time (Adams et al, 2017, 22).

Does she understand what the clock "says" about time? Fortunately, I don't have to get into this murky matter. She does not know that it is 12:00 pm because her belief that it is $12: 00 \mathrm{pm}$ is luckily true. She was lucky to look at the clock at 12:00 pm at the only instant during daylight hours at which its hands could have pointed to the correct time. Adams et al now give the final stage of their argument:

See http://www.lapazlife.com/bolivian-congress-building-getsbackwards-clock/. In this case there is no telling what Gertrude would believe when she first sees the clock, provided she can see the numerals. This is probably why Adams et al stipulate that she cannot read them. Alternatively, we could avoid complication by stipulating that the numerals are arranged conventionally. 
Gertrude's belief isn't based on the clock's saying that it's 12:00 pm, and therefore isn't based on a sensitive reason (Adams et al, 2017, 22).

I am unsure what to make of the premise. It doesn't matter, because the conclusion is false. Surely her reason for believing that it is $12: 00 \mathrm{pm}$ is that the hands of the clock appear to her to be the $12: 00 \mathrm{pm}$ position. That reason is sensitive to it being 12:00 pm. If it were not 12:00 pm but some other time, then the hands of the clock would not appear to her to be in the 12:00 pm position. Instead they would appear to her to be in some other position. For example, if it were 11:55 am, then the clock's hands would appear to her to be in the 12:05 position. This is because the hands move perfectly reliably backwards.

Thus Gertrude has a true belief that it is 12:00 pm based on reasons that are sensitive to the fact that makes it true, that is, reasons that wouldn't obtain if the belief weren't true. But she does not know that it is 12:00. Once again, the ABC analysis is too weak.

\section{IgNORANCE AND LUCK IN THE BACKWARD Chock}

On behalf of Adams et al, one might claim that in Backward Clock you do know that it is $4: 30 \mathrm{pm}$. Indeed, I cannot see any other promising avenue down which they could escape my objection. I have claimed that you do not know that it is 4:30 pm. I have not based this verdict on any appeal to intuition. Nonetheless I do have the strong intuition that you do not know, one I am confident that most will share. Moreover, if any intuition is unassailable, surely it is the intuition that you do not know that it is $4: 30 \mathrm{pm}$ in Stopped Clock. And if you do not know that it is 4:30 pm in 
Stopped Clock then surely you do not know that it is 4:30 pm in Bugged Backward Clock either. Should it be objected that you know that it is 4:30 pm in Bugged Backward Clock but not in Stopped Clock, then surely the onus is on the objector to tell us what the relevant difference is between the two cases.

Rather, my appeal was to luck; you do not know that it is 4:30 pm in Stopped Clock because you are lucky to look at it at exactly 4:30 pm, at the only instant during the hour when you nap at which its hands could point to the correct time. The same is true of Bugged Backward Clock. One way to describe the luck involved is as coincidence. In both cases, since you could have observed the position of the hands of your clock at any time other than 4:30 pm during the hour that you nap, it is a coincidence that the time that you look at the clock is the only time that your resulting belief could be true. In Stopped Clock, it is also a coincidence that the time that it stopped is exactly 24 hours before you observed the position of its hands. Likewise in Bugged Backward Clock, it is a coincidence that the time that its hands jumped to $5: 00 \mathrm{pm}$ is exactly 30 minutes before you observed the position of its hands. In Stopped Clock it is yet another coincidence that the fleck of dust stopped its mechanism at exactly twenty-four hours before you observed the position of its hands rather than some other time. Likewise in Bugged Backward Clock, it is a coincidence that the bug in the programming of its microchip circuit caused its hands to jump from 4:00 pm to 5:00 pm rather than make them behave in other ways —or at least so we may stipulate, holding the effect of the bug to be suitably random. In these ways and in both Stopped Clock and Bugged Backward Clock, it is lucky that your belief that is $4: 30$ pm is true.

It might be insisted that I give a more technical analysis of a "luckily" true belief. I see no reason why I need to do so. Suppose that your method of ascertaining the time that you wake from your nap is to guess what time it is, and to form a corresponding belief based on it. If you guess 
correctly that it is $4: 30 \mathrm{pm}$, surely you do not know that it is 4:30 pm, because your belief is luckily_or coincidentallytrue. The same may be said for your belief that it is $4: 30 \mathrm{pm}$ in both Stopped Clock and Bugged Backward Clock.

It might be further insisted that I give an analysis of knowledge in support of the verdict that you do not know that it is 4:30 pm in Bugged Backward Clock (or Stopped Clock). But this is a an unfair demand, precisely because cases such as Bugged Backward Clock counterexample many such analyses. For example, in our original paper (Williams and Sinhababu, 2015) we showed that Backward Clock uniquely exemplifies a true belief not constituting knowledge, despite being non-trivially sensitive, non-trivially truth-adherent and also safe (roughly meaning that your belief could not easily be false) under three formulations of safety. We also showed that a dispositional formulation of Nozick's analysis proposed by Rachael Briggs and Daniel Nolan (2012) is rendered too weak, as well as a formulation by Duncan Pritchard (2012) that combines a safety condition with a virtue-epistemological one. ${ }^{6}$

${ }^{6}$ However, there is one analysis of knowledge that appears to survive Bugged Backward Clock. This is the later defeasibility theory originating from Klein (1981):

$S$ knows that $p$ just in case she has a justified true belief that $p$ and there is no undefeated defeater $D$ of her justification for believing that $p$

where

$D$ is defeated by $D^{*}$ just in case $D^{*}$ is a truth such that believing it, in addition to believing $D$, preserves her original justification for believing that $p$.

In Normal Clock, you have the true belief that it is $4: 30 \mathrm{pm}$ that is justified by your knowledge that your clock has always worked perfectly reliably as an indicator of the correct time, plus your 


\section{CONCLUDING REMARKS}

Despite Adams et als attempts to evade it, Backward Clock shows that their analysis of knowledge is too weak. Ironically, one of their own examples-Bolivian Backward Clock - is structurally similar to Backward Clock-and even better, to Bugged Backward Clock-with the result that they have counterexampled themselves. Combining this with the range of other analyses of knowledge just mentioned in the last section that fall prey to cases such as Bugged Backward Clock, the broader lesson seems to be that these cases tell us the time is up for purely modal analyses of knowledge.

\section{REFERENCES}

Adams, F., Barker, J. A., \& Clarke, M. "Knowledge as Fact-Tracking True Belief', Manuscrito, 40, pp. 1-30, 2017.

BIRO, J. “Showing the Time,” Analysis, 73, pp. 57-62, 2013.

BRiggs, R., \& Nolan, D. "Mad, Bad and Dangerous to Know," Analysis, 72, pp. 314-16, 2012.

knowledge that its hands point to 4:30 pm. The same is true of Stopped Clock and Bugged Backward Clock. There is no defeater of your belief in Normal Clock. But in Stopped Clock, there is an undefeated defeater of your belief, namely that your clock is stopped, as there is in Backward Clock, namely that the hands of your clock are moving backwards. However I argue elsewhere (Williams 2015) that this analysis should also be rejected, because when you have a posteriori knowledge, it incorrectly prohibits you from knowing that you have it. 
DRETSKE, F. "Conclusive Reasons", Australasian Journal of Philosophy, 49, pp. 1-22, 1971.

KLEIN, P. Certainty: A Refutation of Scepticism. Minneapolis: University of Minnesota Press, 1981.

NozICK, R. Philosophical Explanations, Cambridge, MA: Harvard University Press, 1981.

PRITCHARD, D. “Anti-Luck Virtue Epistemology,” Journal of Philosophy, 109, pp. 247-79, 2012.

Williams, J. N. "Not Knowing You Know: A New Objection to the Defeasibility Theory of Knowledge," Analysis 75, pp. 213-217, 2015.

Williams, J. N., \& SinHababU, N. "The Backward Clock, Truth-Tracking, and Safety", Journal of Philosophy, 112 (1), pp. 46-55, 2015.

$(\mathrm{cc}) \mathbf{E Y}$ 